\title{
NUGGET NOTES: A SIMPLE TEACHING TOOL
}

Kirk Plangger, Simon Fraser University, Canada Michael Parent, Simon Fraser University, Canada

\begin{abstract}
Post-secondary instructors have many demands on their time, however student learning in their classes is one of their most important responsibly. We introduce Nugget Notes, a new teaching tool, that recognizes the time and effort demands felt by professors, busy markers, and of course overwhelmed students. With Nugget Notes being only 100 words, students are compelled to engage with course material, synthesize pertinent information, and apply that knowledge to a real life situation or problem. Student and instructor exploratory surveys support the primary learning goals of Nugget Notes.
\end{abstract}

References available upon request. 